\title{
Health at Every Size: a Weight-neutral Approach for Empowerment, Resilience and Peace
}

\author{
Lily O'Hara ${ }^{1}$, Jane Taylor ${ }^{2}$ \\ ${ }^{1}$ Emirates College for Advanced Education PO Box 126662, Abu Dhabi, United Arab Emirates \\ ${ }^{2}$ University of the Sunshine Coast, Sippy Downs Drive, Sippy Downs QLD 4556, Australia
}

\begin{abstract}
Obesity is high on the agenda of governments and health and welfare agencies worldwide. The placement of body weight at the centre of discourse about health is referred to as the weight-centred health paradigm (WCHP). Critical analysis of the WCHP has increased in recent years, resulting in arguments for a paradigm shift. Critique of the WCHP encompasses ideological, empirical and technical issues. The consequences of the WCHP have been identified as an adipophobicogenic environment (an environment that creates fat hatred and weight stigma), and diminished health, wellbeing and quality of life for people with weight concerns. Many critics argue that it is time for a change of paradigm. The Health at Every Size ${ }^{\circledR}\left(\right.$ HAES) ${ }^{\circledR}{ }^{1}$ approach offers a more salutogenic, compassionate, humane and evidence-based approach to weight concerns. HAES is a strengths-based, ethical approach to enhancing the holistic health and wellbeing of all people. It does not advocate that people are automatically healthy at every size, but that people at every size can be supported to adopt practices that will enhance their health and wellbeing, irrespective of whether these practices result in changes in body weight. The HAES approach aims to empower people to do what they can to improve their health, including developing their resilience and capacity to cope with the trauma of living in a weight centred and adipophobic society. Ultimately, the HAES approach aims to create hope for people to make peace with their bodies.
\end{abstract}

Keywords Health At Every Size, Weight-centred Health, Critique, Paradigm Shift, Peace

\section{Introduction}

Increases in the body weight of people in many countries

\footnotetext{
${ }^{1}$ Health at Every Size ${ }^{\circledR}$ and HAES ${ }^{\circledR}$ are registered service marks of the Association for Size Diversity and Health, acquired for the purpose of ensuring that these terms are only used in reference to health programs or approaches consistent with the Health at Every Size principles. For simplicity, the terms appear without the registered service mark throughout the remainder of this paper.
}

around the world have been the subject of intense scientific, political and media attention, particularly since the turn of the $21^{\text {st }}$ Century (Stearns, 2002; Swinburn \& Egger, 2004; World Health Organization, 2003, 2006). In recent years, the health sector has contributed to the definition of the 'ideal' body established as a contemporary western ideal (Stearns, 2002). The message from health professionals is that pursuing the 'ideal' body is not just an aesthetic imperative; it is also a health imperative. Fat bodies are not simply regarded as undesirable to look at socially, they are labelled as medically compromised (Campos, 2004; Gaesser, 2002; Oliver \& Lee, 2005) and referred to as 'overweight' or 'obese' (Australian Government National Preventative Health Taskforce, 2009).

Rates of obesity are now commonly referred to as 'epidemic', and the consequences of obesity are regarded as medically and psychologically problematic (Swinburn \& Egger, 2004). The dominant message from health authorities is that being overweight or obese is unhealthy, and that all overweight and obese people should lose weight by increasing their physical activity and healthy eating behaviours, in order to improve their health. The placement of body weight at the focal point of discourse about health is referred to as the 'weight-centred health paradigm' (Campos, 2004; Robison, 2003a) and the language of this paradigm uses the terms 'overweight' and 'obesity'.

However, the terms 'overweight' and 'obesity' have been strongly contested and critics argue that such terms serve to medicalise body size and pathologise natural biological variation (Campos, 2004; Wann, 1998). Some critics advocate for the term 'fat' to be used as a neutral relative descriptor in the same way that 'tall' and 'short' are not absolute categories but descriptions of a person's phenotype relative to others (Cooper, 1998; National Association to Advance Fat Acceptance, 2011; Wann, 2005). Using the term 'fat' also represents the political reclamation of a term that is almost universally regarded as negative, in order to defuse its potential for damage (Wann, 1998) and signify it as a political identity (Wann, 2009). Some researchers have found that fat people strongly dislike the terms 'fat' and 'obese' and would rather be called 'overweight' (Thomas, 
Hyde, Karunaratne, Herbert, \& Komesaroff, 2008). Because fatness has become so stigmatised, other researchers have found that parents prefer health care providers to use the term 'unhealthy weight' when referring to their adolescent children (Puhl, Peterson, \& Luedicke, 2011). Throughout this paper, the terms 'overweight' and 'obese' are used if they are the terms used by the study or program being discussed, otherwise the term 'fat' is used.

\section{Weight-centred Health Paradigm}

The term 'paradigm', from Greek, means model, pattern or example (Merriam-Webster Online Dictionary, 2011). Kuhn (1970) proposed that a paradigm is a constellation of beliefs, concepts, ideas and values, together with a set of approaches and techniques that are used by members of a scientific community. The paradigm acts as a guide or a map to what issues should be addressed, the kinds of research questions that should be asked, how questions should be structured, how research should be conducted, how research results should be interpreted, and the types of explanations that are acceptable (Kuhn, 1970). The dominant paradigm is the set of rules that is the most standard and widely held at a given point in time (Barker, 1993).

The weight-centred or weight-normative (Tylka et al., 2014) health paradigm is the dominant paradigm evident in basic and applied scientific inquiry related to body weight, public policy related to body weight, nutrition and physical activity, and the popular media's portrayal of the 'ideal' body (Bacon \& Aphramor, 2011; Campos, Saguy, Ernsberger, Oliver, \& Gaesser, 2006). A range of agents variously described as 'obesity alliances' (Strategies to Overcome and Prevent (STOP) Obesity Alliance), 'obesity crusaders' (Basham \& Luik, 2008), 'obesity alarmists' (Gard, 2011a), 'anti-obesity proponents' (Saguy \& Riley, 2005) or 'obesity epidemic entrepreneurs' (Monaghan, Hollands, \& Pritchard, 2010) are engaged in the enterprising act of socially constructing fatness as a 'correctable' health problem. 'Obesity epidemic entrepreneurs' are characterised as creators, amplifiers/moralizers, legitimators, supporters, enforcers/administrators and the entrepreneurial self (Monaghan, et al., 2010).

The scientific community, particularly the discipline of epidemiology, plays the role of 'creator' through setting benchmarks for the classification of obesity, enumerating the relative risks of morbidity and mortality for each weight classification, and highlighting trends and patterns of obesity (Monaghan, et al., 2010). The popular media play the role of 'amplifier or moralizer' through reporting the scientific 'facts' about obesity produced by the scientific community, framing obesity as a moral issue, and perpetuating the concept of the 'ideal' body for health and beauty (Backstrom, 2012; Barry, Jarlenski, Grob,
Schlesinger, \& Gollust, 2011; Berry, McLeod, Pankratow, \& Walker, 2013; Boero, 2012; Caulfield, Alfonso, \& Shelley, 2009; Holland et al., 2011; Lawrence, 2004; Monaghan, et al., 2010; Saguy \& Gruys, 2010).

Governments, particularly public health departments, play the role of 'legitimator' through establishing anti-obesity task forces (often comprised primarily of medical experts) and commissioning obesity reports (focused predominantly on health economics and modelling future scenarios) (Monaghan, et al., 2010). Furthermore, Governments play the role of 'legitimator' by developing anti-obesity public health policies and programs including surveillance and screening, and public health strategies primarily focused on increasing physical activity and healthy eating choices and creating environments that make such choices the easy choice or the only choice, in order to prevent or reduce 'excess' body weight (Monaghan, et al., 2010).

The weight loss industry is an 'opportunist supporter' by providing weight loss products and services for profit (Monaghan, et al., 2010). In 2010, consumers in the US spent $\$ 60.9$ billion on commercial weight loss products and services, and made an average of four attempts over the year to lose weight (Marketdata Enterprises, 2011). In Australia the weight loss industry, including pills, books, counselling services, surgeries, cookbooks, pre-packaged food and beverages, was estimated to be worth $\$ 790$ million in 2010, with an annual growth over the previous 5 years of $4.1 \%$ (Ibis World, 2011).

Anti-obesity campaigners also play the role of 'supporter' through implementing or mobilising support for anti-obesity campaigns (for example the Strategies to Overcome and Prevent (STOP) Obesity Alliance (Strategies to Overcome and Prevent (STOP) Obesity Alliance)). Health professionals play the role of 'enforcer/administrator' through enforcing or administering the weight rules developed by the scientific committee and legitimated by Governments and offering authoritative advice to health care consumers about the importance of healthy weight and strategies for weight loss.

Finally, slimmers themselves, people engaged in the practice of weight loss, play the role of the 'entrepreneurial self' who display their moral worth and civic responsibility by engaging in weight loss attempts. People engaged in attempted weight loss are also said to have to work to manage the stigma, discrimination and other forms of oppression they face as a result of their body size (Monaghan, et al., 2010).

Those engaged in the construction of weight as an 'obesity epidemic' are operating within a paradigm; a set of rules that establish and define boundaries, and indicate how to behave inside those boundaries to be successful (Kuhn, 1970). The boundaries of the WCHP are established by the claims made about obesity. According to the WCHP, being overweight or obese is said to cause reduced life expectancy and mortality. Obesity, and sometimes even overweight, is 
claimed to 'cause' or 'lead to' cardiovascular disease, type 2 diabetes mellitus, some types of cancer and osteoarthritis. Increases or decreases in body weight are claimed to be caused by a simple imbalance between an individual's energy intake and energy expenditure. Body weight is claimed to be at least partly volitional and within the control of the individual. Increased dietary energy intake and decreased energy expenditure are the most commonly cited causes of increased body weight. Promoting volitional changes to correct this imbalance forms the basis of all major WHO and government anti-obesity public health policies and programs. Altering energy intake and expenditure are claimed to result in successful and sustained weight loss. Environmental change is claimed to contribute significantly to the obesity epidemic. Obesogenic environmental factors are described as those factors that contribute to changes in nutrition and physical activity by making unhealthy behaviours the easy or default choice for people. Creating a less obesogenic environment is claimed to reduce the prevalence of obesity. By focusing on body weight, it is claimed that the purported costs associated with body weight, largely identified through epidemiological and economic modeling studies, will be mitigated.

\section{Critique of the Weight-centred Health Paradigm}

As the WCHP has risen to dominance, so too has the breadth and depth of critique of the paradigm from a broad range of people including academics, journalists, political scientists, lawyers, sociologists, health professionals and members of the community. Numerous research-based books published since the turn of the $21^{\text {st }}$ Century have provided detailed critiques on various aspects of the WCHP (Bacon, 2010; Basham, Gori, \& Luik, 2006; Boero, 2012; Evans, Rich, Davies, \& Allwood, 2008; Gard, 2011b; Gard \& Wright, 2005; Guthman, 2012; Kolata, 2007; LeBesco, 2004; Lupton, 2013; McMichael, 2012; Monaghan, 2008; Oliver, 2006a; Rich, Monaghan, \& Aphramor, 2011; Robison \& Carrier, 2004; Solovay \& Rothblum, 2009; Saguy, 2013; Schatzki, 2011; Solovay, 2000; Wright \& Harwood, 2008). Likewise the volume of critical articles published in the academic literature has increased dramatically. There is also significant critique of the paradigm in popular books (Bacon \& Aphramor, 2014; Cooper, 1998; Wann, 1998), the popular media, and the fatosphere - the collective term for bloggers on the internet that write specifically about fatness (Dickins, Thomas, King, Lewis, \& Holland, 2011; Harding \& Kirby, 2009).

Authors within this body of literature have termed their scholarship 'critical weight studies' (Monaghan, et al., 2010), 'critical obesity studies' (Gard, 2009) or 'fat studies' (Solovay \& Rothblum, 2009). Irrespective of their label, they are united by their critiques of the claims made by the weight-centred health paradigm. Gard characterises those that critique the 'obesity epidemic' and the claims of the 'obesity alarmists' as a 'motley crew' of 'strange bedfellows' that he collectively terms 'obesity sceptics' (Gard, 2011a). He contends that 'obesity sceptics' include 'feminists, queer theorists, libertarians, far right wing conspiracy types and new ageists', and can be categorised as either 'empirical sceptics', who critique the veracity of scientific claims made in the name of the 'obesity epidemic', or 'ideological sceptics' (Gard, 2011a).

Criticisms raised by 'ideological sceptics' (Gard, 2011a) point to the preoccupation of the WCHP with statistics rather than narratives (Carter et al., 2011; Jutel, 2006) and the epistemological presumption of scientific objectivity (Aphramor \& Gingras, 2009; Jutel, 2006). The centrality of the biomedical health paradigm within the WCHP is criticised because the concept of health is reduced to physical health, and physical health status is reduced to a single, medically problematic number (body weight, waist circumference or percentage body fat) (Bacon, 2010; Bacon \& Aphramor, 2011; Evans, 2006). Further critique focuses on the reliance of reductionist science which promulgates the notion that changing body weight or fat is a simple linear process of consciously balancing energy consumption with energy use (Aphramor, 2010; Bacon \& Aphramor, 2011). This assertion leads to the ideological criticism that the WCHP focuses too heavily on individual responsibility for health (through balancing the energy equation) (Monaghan, 2008; Rees, Oliver, Woodman, \& Thomas, 2011; Saguy \& Almeling, 2008), leading to moral judgements and panic, prejudice, bias and stigmatisation of people based on their health status, body size and behaviours (Aphramor \& Gingras, 2009; Boero, 2007; Carr \& Friedman, 2005; Fraser, Maher, \& Wright, 2010; Gard \& Wright, 2005; Heuer, McClure, \& Puhl, 2011; Lawrence, Hazlett, \& Abel, 2011; LeBesco, 2011; MacLean et al., 2009; Pomeranz, 2008; Puhl \& Heuer, 2010; Rich \& Evans, 2005; Ronald, 2008; Saguy \& Gruys, 2010; Saguy \& Almeling, 2008; Schafer \& Ferraro, 2011; Teixeira \& Budd, 2010; Thomas, Lewis, Hyde, Castle, \& Komesaroff, 2010; Thompson \& Kumar, 2011). Further consequences include unwarranted governmental and social surveillance and regulation of the behaviours and bodies of children and adults (Basham, et al., 2006; Center for Consumer Freedom, 2004; Ikeda, Crawford, \& Woodward-Lopez, 2006; Kaczmarski, DeBate, Marhefka, \& Daley, 2011; Nihiser et al., 2009; Rich, 2010) - inequitably experienced by women, the poor and minorities - and greater inequalities in health (Dolgin \& Dieterich, 2011; Friel, Chopra, \& Satcher, 2007; Gard, 2011a; Rail, Holmes, \& Murray, 2010; Saguy \& Riley, 2005).

A significant thread in the ideological critique of the WCHP relates to the role of the free market and the undue power and influence that profit-making organisations (such as pharmaceutical, fitness and commercial weight loss companies) have on scientific decision-making about body weight and public health policy. This critique about conflict of interest is taken up by those focusing on ideological 
issues as well as the empirical sceptics (Bacon, 2010, 2011; Campos, 2004; Center for Consumer Freedom, 2004; Monaghan, 2008; Moynihan, 2006; Oliver, 2006b; Robison \& Carrier, 2004; Saguy \& Riley, 2005; Vander Schee \& Boyles, 2010; Wann, 2005). Gingras (2005) further argues that such conflicts of interest are not only problematic from the perspectives of transparency and expectations of reciprocity, they also serve to undermine trust in health professionals and professional associations that directly or indirectly receive support.

Criticisms about the WCHP raised by 'empirical sceptics' (Gard, 2011a) revolve around three major issues: inaccuracy, ineffectiveness and unintended harmful consequences. The criticisms about inaccuracy focus on questions about the veracity or interpretation of data on changes in average body weight and the relationships between body weight, morbidity and mortality (Basham, et al., 2006; Campos, 2004; Campos, et al., 2006; Ernsberger \& Koletsky, 2000; Gaesser, 2002; Gard \& Wright, 2005; Mitchell \& McTigue, 2007; Monaghan, 2005; Oliver, 2006a; Pieterman, 2007), the inappropriateness of the terms and language used to describe the extent of these changes (including the 'epidemic' discourse) (Basham \& Luik, 2008; Boero, 2007; Campos, et al., 2006; Gard, 2011b; Herndon, 2005; Rail, et al., 2010), and the misrepresentation of correlation as cause (Bacon, 2010; Gaesser, 2002; Gard \& Wright, 2005; Robison \& Carrier, 2004). Basham and Luik (2008) express significant concern about the deliberate exaggeration or, indeed, outright misrepresentation of the risks of obesity, and that the implications of such practices "for science policy and for evidence-based medicine dwarf those of any obesity epidemic, real or imagined" (Basham \& Luik, 2008, p. 244).

The second set of 'empirical criticisms' (Gard, 2011a) point to the ineffectiveness of the 'war on obesity' and 'obesity prevention' programs. Critics point to the lack of evidence of effectiveness for weight loss programs at the individual level, and obesity prevention programs at the group, community and population level (Aphramor, 2010; Ernsberger \& Koletsky, 2000; Gaesser, 2009; Guthman, 2012; Ikeda et al., 2005; Kolata, 2007). The ineffectiveness of weight loss programs gives rise to a sense of hopelessness and disempowerment in those trying to lose weight and keep it off. The third major set of criticisms draw on the empirical evidence of harms arising from the WCHP including body dissatisfaction, disordered eating, weight cycling, stigma and body size discrimination (Aphramor, 2005; Bacon \& Aphramor, 2011; Bell, McNaughton, \& Salmon, 2009; Catling \& Malson, 2012; Cogan \& Ernsberger, 1999; Cooper, 2010; Ikeda, et al., 2006; Kassirer \& Angell, 1998; Lawrence, et al., 2011; MacLean, et al., 2009; Pieterman, 2007; Puhl \& Heuer, 2010; Rees, et al., 2011). The current environment in which body weight is so strongly stigmatised can be regarded as 'adipophobicogenic' - an environment which creates fat phobia and its numerous sequelae (O'Hara, 2014). The 'war on obesity' is a war against fat people, who bear the brunt of the casualties. However it is not just fat people that are suffering under this war: people of all sizes are disempowered by medically and socially sanctioned fat phobia.

Finally, the WCHP has been subject to critiques on the basis of technical concerns. Public health programs operating within the WCHP use a limited range of deficit oriented strategies, rather than a portfolio of multiple strategies that build on strengths and assets (O'Hara, 2014). Health professionals implementing WCHP public health programs are cast as experts who intervene on people, rather than allies who work with people (O'Hara, 2014). The focus of evaluation in WCHP public health programs is limited to biomedical risk factors and behaviours (Carter, et al., 2011; O'Hara, 2014).

In summary, weight-related public health initiatives are now being subjected to extensive critique based on ideological, empirical and technical grounds. Ideological critique has highlighted philosophical, ethical and human rights concerns. Empirical critique has identified concerns about the quality and nature of evidence supporting the WCHP, and evidence of unintended harms or iatrogenic outcomes. Technical critique has focused on the use of limited, deficit-oriented strategies in policies and programs, the role of health professionals as experts rather than allies, and the use of limited, biomedical-focused evaluation. As a result of these critiques, alternative, weight-inclusive approaches to health and body weight have been developed.

\section{Health at Every Size Approach}

Within the weight-inclusive health paradigm, weight is viewed as one of many interconnected, complex aspects of health and wellbeing, and not the centre or focus of health and wellbeing (Tylka, et al., 2014). The Health at Every Size (HAES) approach is one example of a weight-inclusive approach which moves the focus away from weight and towards health and wellbeing (Association for Size Diversity and Health (ASDAH), 2014; Bacon, 2010; Bacon \& Aphramor, 2011; Bacon, Stern, Van Loan, \& Keim, 2005; Kater, 2004; Kratina, 2004; Robison, 2003b; Robison, Putnam, \& McKibbin, 2007a, 2007b; Wann, 2005). The HAES approach supports processes that enhance the health of all people, irrespective of their body size or weight. It does not contend that people are healthy at any size; instead the approach contends that people at any size can be empowered to focus on improving their health by adopting behaviours that are not focused on body weight. This more peaceful approach to health and bodies evolved from what was initially called the non-diet movement (Bacon et al., 2002).

The values and principles of the HAES approach have been proposed by a range of writers and have evolved from those focused on individuals (ASDAH, 2014; Bacon, 2006, 
2010; Bacon, et al., 2005; Kater, 2004; Kratina, 2004; Robison, 2003a; Robison \& Carrier, 2004; Wann, 2005) through to a broader level approach which also includes a focus on the social, cultural, political and environmental factors (ASDAH, 2014; Bacon \& Aphramor, 2014; Tylka, et al., 2014). The primary value of the HAES approach is non-maleficence; to do no harm (Tylka, et al., 2014). Underpinning the HAES approach at all levels is the value of critical awareness, which is enacted through the principles of challenging scientific and cultural assumptions, valuing people's body knowledge and their lived experiences, and acknowledging social injustice and the role of disadvantage and oppression as health hazards (Bacon \& Aphramor, 2014). The Association for Size Diversity and Health lists the following HAES values: weight inclusivity, holistic health enhancement, respectful care, eating for wellbeing, and life-enhancing movement (ASDAH, 2014).

The value of holistic health enhancement is enacted by developing and supporting health policies that improve and equalize access to information, services and health promoting environments. For example, this includes: health service standards for best practice in the provision of care for people at higher weights; policies to ensure the provision of nourishing, affordable and accessible food in schools; town planning regulations to enhance opportunities for physical activity, social connectivity and engagement with nature; policies and procedures that ensure community involvement in decision making; legislation to prohibit weight-based discrimination; regulation of the weight loss industry; and taxation and fiscal policy to reduce income inequity (Tylka, et al., 2014).

The value of holistic health enhancement is also enacted by supporting empowering personal practices that improve human wellbeing and resilience, including attention to individual physical, economic, social, spiritual, emotional, and other needs. The value of weight inclusivity is enacted by accepting and respecting the inherent variety of body shapes and sizes - making peace with our bodies and celebrating their rich diversity. The value of respectful care is enacted by acknowledging our biases, and working to end weight discrimination, weight stigma, and weight bias. Furthermore, respectful care requires providing information and services from an understanding that socio-economic status, race, gender, sexual orientation, age, and other identities impact weight stigma, and supporting environments that address these inequities.

The value of eating for wellbeing is enacted by empowering people to pursue flexible, individualized eating based on hunger, satiety, nutritional needs, and pleasure, rather than any externally regulated eating plan focused on weight control. And finally, the value of life-enhancing movement is enacted by empowering people of all sizes, abilities, and interests to engage in enjoyable movement, to the degree that they choose.

The HAES approach also explicitly opposes a number of concepts. Adopting a HAES approach involves uncoupling the concepts of health and 'ideal' weight, and contesting the notion that health can be defined by an 'ideal' body mass index, body weight, waist circumference or percentage body fat. The pursuit of deliberate weight loss, including the use of dieting, drugs, programs, products or surgery for the primary purpose of weight loss is not consistent with a HAES approach.

The HAES approach does not support assumptions that a person's body size, weight or body mass index is evidence of a particular way of eating, physical activity level, personality, psychological state, moral character or health status. Furthermore, the HAES approach actively challenges body size oppression, including bias, exploitation, marginalisation, discrimination, powerlessness, cultural imperialism, harassment or violence against people based on their body image, body size or weight. The HAES approach also challenges any approach to health, eating or exercise, the provision of products, services or amenities which focuses on body weight or perpetuates body size oppression. Finally, the HAES approach actively challenges healthism, an ideology in which individuals are deemed to have total responsibility for their health, are morally obliged to pursue the goal of perfect health, and are personally blamed if they get sick.

The HAES approach has been demonstrated to be effective in improving various health indicators for individuals. Eight studies (Bacon, et al., 2005; Ciliska, 1998; Gagnon-Girouard et al., 2010; Goodrick, Poston 1l, Kimball, Reeves, \& Foreyt, 1998; Mensinger, Close, \& Ku, 2009; Provencher et al., 2009; Rapoport, Clark, \& Wardle, 2000; Tanco, Linden, \& Earle, 1998) have used randomised control trials to test a HAES program against standard care or alternative obesity treatment options in individuals. A review of six of these studies (Bacon \& Aphramor, 2011) together with the results from two other studies (Gagnon-Girouard, et al., 2010; Mensinger, et al., 2009) demonstrated that the HAES approach was as effective or superior to the alternative approach in improving many health indicators. The HAES approach improved physiological factors included systolic blood pressure (Bacon, et al., 2005), diastolic blood pressure (Ciliska, 1998) and low density lipoprotein (Bacon, et al., 2005). Improved psychological factors included self-esteem (Bacon, et al., 2005; Ciliska, 1998), depression (Bacon, et al., 2005), body dissatisfaction (Bacon, et al., 2005; Ciliska, 1998), body image (Bacon, et al., 2005), body esteem related to appearance (Gagnon-Girouard, et al., 2010), body esteem related to weight (Gagnon-Girouard, et al., 2010), interoceptive awareness (Bacon, et al., 2005), depression (Ciliska, 1998; Tanco, et al., 1998), anxiety (Tanco, et al., 1998), eating-related psychosocial pathology (Tanco, et al., 1998), perception of self-control (Tanco, et al., 1998), and quality of life related to weight (Gagnon-Girouard, et al., 2010). Improved behavioural factors included binge eating (Bacon, et al., 2005; Ciliska, 1998; Gagnon-Girouard, et al., 2010), disinhibition (Provencher, et al., 2009), susceptibility to hunger (Provencher, et al., 2009), global disordered 
eating (Mensinger, et al., 2009), intuitive eating (Mensinger, et al., 2009) and moderate level physical activity (Bacon, et al., 2005).

\section{Health at Every Size Community Based Programs}

Evaluation studies have also demonstrated the benefits of the HAES approach in both educational and other community environments. HAES school curricula have resulted in improvements in children's self-esteem and body image in the USA (Kater, Rohwer, \& Londre, 2002) and teachers' knowledge, attitudes, beliefs and teaching skills, including their ability to design and implement a curriculum unit consistent with the holistic, ecological model of health and syllabus requirements in Australia (Shelley, O'Hara, \& Gregg, 2010). A HAES based university general education course in the USA resulted in statistically significant improvements in students' intuitive eating, restrained eating, dieting, and body image (Clifford, Humphrey, \& Morris, 2013).

Community based programs in different parts of the world have seen similar results. WISEWOMAN, a HAES oriented program for Alaskan Native and low-income, rural, non-Native women in south-east Alaska resulted in measured improvements in fitness and cardiovascular risk scores, and self-reported improvements in body image and physical activity (Meyer \& Natwick, 2013). Evaluation of the 10 week HUGS (Health focused, centred on Understanding lifestyle behaviours, Group supported, and Self-esteem building) program (Omichinski, 2008) in Canada demonstrated reductions in negative behaviours such as restrictive dieting, and improving self-esteem and self-nourishment (Lehmann, Ciliska, Ernsberger, \& Omichinski, 2000; Omichinski \& Harrison, 1995). Well Now is an eight session course offered by a UK non-profit organisation Well Founded (Aphramor, no date). Evaluation of a Well Now pilot program in Scotland demonstrated statistically significant improvements in a range of mental wellbeing indicators including self-esteem, positive thoughts and feelings and personal resilience (MacDonald \& Clarke, 2013). The program also resulted in statistically significant improvements in a range of food behaviours including eating to appetite, the quality, quantity and variety of foods eaten, and guilt and shame around eating. All improvements were independent of weight loss.

\section{Critique of the Health at Every Size Approach}

The HAES approach is not without its critics, many of whom have expressed their concerns with the accuracy and consequences of adopting this alternative, weight-inclusive paradigm. In many cases these criticisms have been not been framed explicitly as criticisms of the HAES approach, but rather of the 'fat acceptance' movement (Saguy \& Riley, 2005). However the HAES approach and fat acceptance movement are not synonymous, with fat acceptance focusing more broadly on the social and political issues related to size diversity, compared to the HAES approach which focuses specifically on improving health.

Specific criticism of the HAES approach has focused on the principles of the approach. Lupton (2012) raised a number of concerns about the paradigm from a sociological perspective. She argued that the HAES principles, with their explicit focus on attaining good health, can be perceived as healthism. The 'healthist' potential of the HAES approach has also been criticised by others (Brady, Gingras, \& Aphramor, 2013; Burgard, 2009; Welsh, 2011).

Further criticism from Lupton (2012) focused on the principle that people tune in to their natural desires and cues related to eating, as this does not acknowledge the social, cultural and other drivers of food consumption. She also criticised the principle of respecting and appreciating the rich diversity and natural distribution of body shapes and sizes. She particularly focused on the application of this principle to the self, and argued that asking people to value or love their own body does nothing to address the social stigma and discrimination against fat bodies (Lupton, 2012).

One criticism that has been applied to both the HAES approach and the WCHP is that scientific, objectivist knowledge is privileged over other forms of knowledge in arguing for and against the approach or paradigm. LeBesco (2010) argued that the use of scientific arguments by critical weight scholars to refute many of the claims made by anti-obesity scholars simply reinforces fatness as a biomedicalised and pathologised state. Brady et al. (2013) counter that the use of scientific arguments does not necessarily constitute healthism, though do not deny that such arguments can be used in this way. The most recent versions of HAES principles published by the Association for Size Diversity and Health (2014), Bacon and Aphramor (2014), and Tylka et al. (2014) attempt to address these criticisms by broadening the scope of the HAES approach beyond the individual to include the social, cultural, political and environmental determinants of health.

\section{Conclusion}

The weight-centred health paradigm continues to be the dominant paradigm with respect to body weight. However this paradigm has been strongly critiqued on ideological, empirical and technical grounds. An alternative approach within the weight-neutral or weight-inclusive paradigm is the Health at Every Size approach. The results of numerous randomised controlled trials and quasi-experimental studies provide a growing evidence base for the effectiveness of the HAES approach. If improvements in health and wellbeing 
are the goal, then the HAES approach is more effective than traditional weight-centred approaches. Furthermore, given the ineffectiveness of traditional weight-centred approaches in improving health and wellbeing, and the harm that such approaches can result in, there is a strong argument that continued recommendation of traditional weight-centred approaches is unethical.

The HAES approach empowers individuals to practice mindful self-care, rather than self-hate or disgust. It offers hope for a world in which people's bodies (all bodies) are valued, cherished and nurtured rather than battled against and stigmatised. Adopting a HAES approach assists people to develop their resilience and capacity to cope with the trauma of living in a weight centred and adipophobic society. The HAES approach empowers health and other social service workers to reject the dominant, malfunctioning paradigm and adopt a practice grounded in ethics and evidence that draws on people's individual and collective strengths. Health at Every Size is a peace movement that could truly change the world.

\section{REFERENCES}

Aphramor, L. (2005). Is A Weight-Centred Health Framework Salutogenic? Some Thoughts on Unhinging Certain Dietary Ideologies. Social Theory \& Health, 3(4), 315.

Aphramor, L. (2010). Validity of claims made in weight management research: a narrative review of dietetic articles. Nutrition Journal, 9(1), 30.

Aphramor, L. (no date). Well Founded Retrieved 13 Aug, 2014

Aphramor, L., \& Gingras, J. (2009). That Remain to Be Said: Disappeared Feminist Discourses on Fat in Dietetic Theory and Practice. In E. Rothblum \& S. Solovay (Eds.), The Fat Studies Reader (pp. 97-105). New York: New York University Press.

Association for Size Diversity and Health. (2014). HAES Principles Retrieved 9 August, 2014, from

http://www.sizediversityandhealth.org/content.asp?id=76

Backstrom, L. (2012). From the Freak Show to the Living Room: Cultural Representations of Dwarfism and Obesity. Sociological Forum, 27(3), 682-707. doi: 10.1111/j.1573-7861.2012.01341.x

Bacon, L. (2006). End the war on obesity: make peace with your patients. Medscape General Medicine, 8(4), 40.

Bacon, L. (2010). Health at Every Size: The Surprising Truth About Your Weight (2nd ed.). Dallas, TX, USA: BenBella Books.

Bacon, L., \& Aphramor, L. (2011). Weight Science: Evaluating the Evidence for a Paradigm Shift. Nutrition Journal, 10(9).

Bacon, L., \& Aphramor, L. (2014). Body Respect: What Conventional Health Books Get Wrong, Leave Out, and Just Plain Fail to Understand about Weight. Dallas, TX: BenBella Books Inc.

Bacon, L., Stern, J. S., Van Loan, M. D., \& Keim, N. L. (2005). Size Acceptance and Intuitive Eating Improve Health for Obese, Female Chronic Dieters. Journal of the American Dietetic Association, 105(6), 929-936.
Barker, J. A. (1993). Paradigms: The Business of Discovering the Future. New York, NY, USA: Harper Collins.

Barry, C. L., Jarlenski, M., Grob, R., Schlesinger, M., \& Gollust, S. E. (2011). News Media Framing of Childhood Obesity in the United States From 2000 to 2009. Pediatrics, 128(1), 132-145. doi: 10.1542/peds.2010-3924

Basham, P., Gori, G., \& Luik, J. (2006). Diet Nation: Exposing the Obesity Crusade. London: Social Affairs Unit.

Basham, P., \& Luik, J. (2008). Is the obesity epidemic exaggerated? Yes. British Medical Journal, 336(7638), 244. doi: 10.1136/bmj.39458.480764.AD

Bell, K., McNaughton, D., \& Salmon, A. (2009). Medicine, morality and mothering: public health discourses on foetal alcohol exposure, smoking around children and childhood overnutrition. Critical Public Health, 19(2), 155 - 170.

Berry, T. R., McLeod, N. C., Pankratow, M., \& Walker, J. (2013). Effects of Biggest Loser Exercise Depictions on Exercise-Related Attitudes. American Journal of Health Behavior, 37(1), 96-103. doi: 10.5993/ajhb.37.1.11

Boero, N. (2007). All the News that's Fat to Print: The American "Obesity Epidemic" and the Media. Qualitative Sociology, 30(1), 41-60.

Boero, N. (2012). Killer Fat: Media, Medicine and Morals in the American "Obesity Epidemic". New Brunswick, NJ: Rutgers University Press.

Brady, J., Gingras, J., \& Aphramor, L. (2013). Theorizing health at every size as a relational-cultural endeavour. Critical Public Health, 23(3), 345-355. doi: 10.1080/09581596.2013.797565

Burgard, D. (2009). What is "Health at Every Size"? In E. Rothblum \& S. Solovay (Eds.), The Fat Studies Reader (pp. 42-53). New York, NY, USA: New York University Press.

Campos, P. (2004). The Obesity Myth New York: Gotham Books.

Campos, P., Saguy, A., Ernsberger, P., Oliver, E., \& Gaesser, G. (2006). The epidemiology of overweight and obesity: public health crisis or moral panic? International Journal of Epidemiology, 35(1), $55-60$.

Carr, D., \& Friedman, M. A. (2005). Is Obesity Stigmatizing? Body Weight, Perceived Discrimination, and Psychological Well-Being in the United States. Journal of Health and Social Behavior, 46(3), 244.

Carter, S. M., Rychetnik, L., Lloyd, B., Kerridge, I. H., Baur, L., Bauman, A., Hooker, C., Zask, A. (2011). Evidence, Ethics, and Values: A Framework for Health Promotion. American Journal of Public Health, 101(3), 465-472. doi: 10.2105/ajph.2010.195545

Catling, L., \& Malson, H. (2012). Feeding a fear of fatness? The discursive construction of anti-obesity health promotion campaigns in accounts of women with a history of an 'eating disorder'. Psychology of Women Section Review, in press.

Caulfield, T., Alfonso, V., \& Shelley, J. (2009). Deterministic?: Newspaper Representations of Obesity and Genetics The Open Obesity Journal, 1, 38-40. doi: doi:

$10.2174 / 1876823700901010038$

Center for Consumer Freedom. (2004). An Epidemic Of Obesity Myths. Washington DC, USA: Center for Consumer Freedom.

Ciliska, D. (1998). Evaluation of Two Nondieting Interventions 
for Obese Women. Western Journal of Nursing Research, 20(1), 119-135. doi: 10.1177/019394599802000108

Clifford, D., Humphrey, L., \& Morris, M. N. (2013). Health at Every Size: A New Opportunity for General Education. Journal of Nutrition Education and Behavior, 45(4), S4-S5. doi: 10.1016/j.jneb.2013.04.016

Cogan, J. C., \& Ernsberger, P. (1999). Dieting, Weight, and Health: Reconceptualizing Research and Policy. Journal of Social Issues, 55(2), 187-205.

Cooper, C. (1998). Fat and Proud: The Politics of Size. London, UK: Women's Press.

Cooper, C. (2010). Olympics/Uhlympics: Living in the Shadow of the Beast. thirdspace: a journal of feminist theory \& culture, $9(2)$.

Dickins, M., Thomas, S. L., King, B., Lewis, S., \& Holland, K. (2011). The Role of the Fatosphere in Fat Adults' Responses to Obesity Stigma: A Model of Empowerment Without a Focus on Weight Loss. Qualitative Health Research. doi: $10.1177 / 1049732311417728$

Dolgin, J. L., \& Dieterich, K. R. (2011). Weighing Status: Obesity, Class, and Health Reform. Oregon Law Review, 89(4), 1113-1176.

Ernsberger, P., \& Koletsky, R. J. (2000). Part 2: Rationale for a Wellness Approach to Obesity. Healthy Weight Journal, 14(2), 20.

Evans, B. (2006). 'Gluttony or sloth': critical geographies of bodies and morality in (anti)obesity policy. Area, 38(3), 259-267.

Evans, J., Rich, E., Davies, B., \& Allwood, R. (2008). Education, disordered eating and obesity discourse: fat fabrications. Oxon, UK: Routledge.

Fraser, S., Maher, J., \& Wright, J. (2010). Between bodies and collectivities: Articulating the action of emotion in obesity epidemic discourse. Social Theory and Health, 8(2), 192-209.

Friel, S., Chopra, M., \& Satcher, D. (2007). Unequal weight: equity oriented policy responses to the global obesity epidemic. British Medical Journal, 335(7632), 1241-1243. doi: 10.1136/bmj.39377.622882.47

Gaesser, G. A. (2002). Big Fat Lies: The Truth About Your Weight and Your Health. Carlsbad, CA: Gurze Books.

Gaesser, G. A. (2009). Is "Permanent Weight Loss" an Oxymoron? The Statistics on Weight Loss and the National Weight Control Registry. In E. Rothblum \& S. Solovay (Eds.), The Fat Studies Reader. New York, NY, USA: New York University Press.

Gagnon-Girouard, M.-P., Begin, C., Provencher, V., Tremblay, A., Mongeau, L., Boivin, S., \& Lemieux, S. (2010). Psychological Impact of a "Health-at-Every-Size" Intervention on Weight-Preoccupied Overweight/Obese Women. Journal of Obesity, 2010(Article ID 928097), 12 pages. doi: $10.1155 / 2010 / 928097$

Gard, M. (2009). Friends, Enemies and the Cultural Politics of Critical Obesity Research. In J. Wright \& V. Harwood (Eds.), Biopolitics and the 'Obesity Epidemic': Governing Bodies. Abingdon: Routledge.

Gard, M. (2011a). Truth, belief and the cultural politics of obesity scholarship and public health policy. Critical Public Health, 21(1), 37-48. doi: 10.1080/09581596.2010.529421
Gard, M. (2011b). The End of the Obesity Epidemic. Oxon, UK: Routledge.

Gard, M., \& Wright, J. (2005). The Obesity Epidemic: Science, Morality and Ideology. Abingdon: Routledge.

Gingras, J. (2005). Evoking trust in the nutrition counselor: why should we be trusted? Journal of Agricultural and Environmental Ethics, 18(1), 57-74. doi: 10.1007/s10806-004-3092-3

Goodrick, G. K., Poston 1l, W. S. C., Kimball, K. T., Reeves, R. S., $\&$ Foreyt, J. P. (1998). Nondieting versus dieting treatment for overweight binge-eating women. Journal of Consulting and Clinical Psychology, 66, 363-368.

Guthman, J. (2012). Weighing In: Obesity, Food Justice, and the Limits of Capitalism. Berkley, CA, USA: University of California Press.

Harding, K., \& Kirby, M. (2009). Lesson from the Fat-o-sphere. New York, NY, USA: Penguin Group.

Herndon, A. M. (2005). Collateral Damage from Friendly Fire?: Race, Nation, Class and the "War Against Obesity". Social Semiotics, 15(2), 127-141. doi: 10.1080/10350330500154634

Heuer, C. A., McClure, K. J., \& Puhl, R. M. (2011). Obesity Stigma in Online News: A Visual Content Analysis. Journal of Health Communication, 16(9), 976-987. doi: 10.1080/10810730.2011.561915

Holland, K. E., Blood, R. W., Thomas, S. I., Lewis, S., Komesaroff, P. A., \& Castle, D. J. (2011). 'Our girth is plain to see': An analysis of newspaper coverage of Australia's Future 'Fat Bomb'. Health, Risk \& Society, 13(1), 31-46. doi: 10.1080/13698575.2010.540648

Ibis World. (2011). Weight Loss Services in Australia: Market Research Report Retrieved 9 November, 2011, from http://www.ibisworld.com.au/industry/default.aspx?indid=1704

Ikeda, J., Amy, N. K., Ernsberger, P., Gaesser, G. A., Berg, F. M., Clark, C. A., Parham, E. S., \& Peters, P. (2005). The National Weight Control Registry: A Critique. Journal of Nutrition Education \& Behavior, 37(4), 203-205.

Ikeda, J. P., Crawford, P. B., \& Woodward-Lopez, G. (2006). BMI screening in schools: helpful or harmful. Health Education Research, 21(6), 761. doi: doi:10.1093/her/cyl144

Jutel, A. (2006). The emergence of overweight as a disease entity: Measuring up normality. Social Science \&amp; Medicine, 63(9), 2268-2276. doi: 10.1016/j.socscimed.2006.05.028

Kaczmarski, J. M., DeBate, R. D., Marhefka, S. L., \& Daley, E. M. (2011). State-Mandated School-Based BMI Screening and Parent Notification. Health Promotion Practice, 12(6), 797-801. doi: $10.1177 / 1524839911419289$

Kassirer, J. P., \& Angell, M. (1998). Losing Weight - An Ill-Fated New Year's Resolution. New Englang Journal of Medicine, 338(1), 52-54. doi: 10.1056/nejm199801013380109

Kater, K. J. (2004). Using the Health At Every Size Approach with Children: Case Example. Health at Every Size, 18(2), 28-30.

Kater, K. J., Rohwer, J., \& Londre, K. (2002). Evaluation Of An Upper Elementary School Program To Prevent Body Image, Eating And Weight Concerns. Journal of School Health, 72(5), $1-21$. 
Kolata, G. (2007). Rethinking Thin: The New Science of Weight Loss - and the Myths and Realities of Dieting. New York: Farrar, Straus and Giroux.

Kratina, K. (2004). Health At Every Size (Nondiet) Approach to Weight and Health (pp. 1-19). Gainesville, FL: University of Florida.

Kuhn, T. (1970). The Structure of the Scientific Revolution. Chicago, IL, USA: University of Chicago Press.

Lawrence, R. G. (2004). Framing Obesity: The Evolution of News Discourse on a Public Health Issue. Harvard International Journal of Press/Politics, 9(3), 56-75. doi: 10.1177/1081180x04266581

Lawrence, S. A., Hazlett, R., \& Abel, E. M. (2011). Obesity Related Stigma as a Form of Oppression: Implications for Social Work Education. Social Work Education. doi: 10.1080/02615479.2010.541236

LeBesco, K. (2004). Revolting bodies? The struggle to redefine fat identity. Amherst, MA, USA: University of Massachusetts Press.

LeBesco, K. (2010). Fat Panic and the New Morality. In J. J. Metzl \& A. Kirkland (Eds.), Against Health: How Health Became

the New Morality (pp. 72-82). New York, NY: University Press.

LeBesco, K. (2011). Neoliberalism, public health, and the moral perils of fatness. Critical Public Health, 21(2), 153-164. doi: 10.1080/09581596.2010.529422

Lehmann, B., Ciliska, D., Ernsberger, P., \& Omichinski, L. (2000). Impact of a Nutrition and Support Program for the Obese Not Centred on Weight Loss: Pilot Study of HUGS Outcomes Retrieved 14 April, 2008, from

http://www.hugs.com/01 facilitator/adultprograms/HugsEfficacyP DF.pdf

Lupton, D. (2012, 25 September). A sociological critique of the Health at Every Size movement. online Retrieved from http://simplysociology.wordpress.com/2012/09/24/a-sociological-c ritique-of-the-health-at-every-size-movement/

Lupton, D. (2013). Fat. Oxon, UK: Routledge.

MacDonald, V., \& Clarke, F. (2013). A Health at Every Size (HAES) alternative to traditional weight loss approaches - a pilot. Inverness, Scotland: NHS Highland.

MacLean, L., Edwards, N., Garrard, M., Sims-Jones, N., Clinton, K., \& Ashley, L. (2009). Obesity, stigma and public health planning. Health Promotion International, 24(1), 88-93. doi: 10.1093/heapro/dan041

Marketdata Enterprises, I. (2011). U.S. Weight Loss \& Diet Control Market (11 ed.). Tampa, FL, USA.

McMichael, L. (2012). Talking Fat: Health vs. Persuasion in the War On Our Bodies. Nashville, TN: Pearlsong Press.

Mensinger, J., Close, H., \& Ku, J. (2009). Intuitive Eating: A novel health promotion strategy for obese women. Paper presented at the American Public Health Association Conference, Philadelphia, PA.

http://apha.confex.com/apha/137am/webprogram/Paper196751.ht $\mathrm{ml}$

Merriam-Webster Online Dictionary. (2011). Paradigm definition Retrieved 9 August 2011, from

http://www.merriam-webster.com/dictionary/paradigm
Meyer, J., \& Natwick, K. (2013). Wise at Every Size: A Program for Women of Southeast Alaska to Increase Fitness and Reduce Chronic Disease Risk. Journal of Nutrition Education and Behavior, 45(4), S5. doi: 10.1016/j.jneb.2013.04.016

Mitchell, G. R., \& McTigue, K. M. (2007). The US Obesity "Epidemic": Metaphor, Method, or Madness? Social Epistemology: A Journal of Knowledge, Culture and Policy, 21(4), 391 - 423.

Monaghan, L. F. (2005). Discussion Piece: A Critical Take on the Obesity Debate. Social Theory \& Health, 3(4), 302.

Monaghan, L. F. (2008). Men and the war on obesity: a sociological study. Oxon, UK: Routledge.

Monaghan, L. F., Hollands, R., \& Pritchard, G. (2010). Obesity Epidemic Entrepreneurs: Types, Practices and Interests. Body \& Society, 16(2), 37-71. doi: 10.1177/1357034x10364769

Moynihan, R. (2006). Obesity task force linked to WHO takes "millions" from drug firms. BMJ, 332(17 June), 1412.

National Association to Advance Fat Acceptance. (2011). Home page Retrieved 9 August, 2011, from http://www.naafaonline.com/ dev2/index.html

Nihiser, A. J., Lee, S. M., Wechsler, H., McKenna, M., Odom, E., Reinold, C., Thompson, D., \& Grummer-Strawn, L. (2009). BMI Measurement in Schools. Pediatrics, 124(Supplement 1), S89-97. doi: $10.1542 /$ peds.2008-3586L

O'Hara, L. (2014). The extent to which weight-related public health initiatives reflect the values and principles of health promotion: a critical discourse analysis. $\mathrm{PhD}$, University of the Sunshine Coast, Sippy Downs. Retrieved from http://research.usc.edu.au/vital/access/manager/Repository/usc:135 93

Oliver, J. E. (2006a). Fat Politics: The Real Story Behind America's Obesity. New York: Oxford University Press.

Oliver, J. E. (2006b). The Politics of Pathology: how obesity became an epidemic disease. Perspectives in Biology and Medicine, 49(4), 611-627.

Oliver, J. E., \& Lee, T. (2005). Public Opinion and the Politics of Obesity in America. Journal of Health Politics, Policy \& Law, 30(5), 923-954.

Omichinski, L. (2008). HUGS International Retrieved 10 April 2008, from http://www.hugs.com/index.htm

Omichinski, L., \& Harrison, K. R. (1995). Reduction of Dieting Attitudes and Practices after participation in a Non-Diet Lifestyle Program. Journal of the Canadian Dietetic Association, 56, 81-85.

Pieterman, R. (2007). The Social Construction of Fat: Care and Control in the Public Concern for Healthy Behaviour. Sociology Compass, 1(1), 309-321. doi: 10.1111/j.1751-9020.2007.00009.x

Pomeranz, J. L. (2008). A Historical Analysis of Public Health, the Law, and Stigmatized Social Groups: The Need for Both Obesity and Weight Bias Legislation. Obesity, 16(S2), S93-S103.

Provencher, V., Bégin, C., Tremblay, A., Mongeau, L., Corneau, L., Dodin, S., Boivin, S., \& Lemieux, S. (2009). Health-At-Every-Size and Eating Behaviors: 1-Year Follow-Up Results of a Size Acceptance Intervention. Journal of the American Dietetic Association, 109(11), 1854-1861. doi: 10.1016/j.jada.2009.08.017

Puhl, R. M., \& Heuer, C. (2010). Obesity Stigma: Important 
Considerations for Public Health. American Journal of Public Health, 100(6), 1019.

Puhl, R. M., Peterson, J. L., \& Luedicke, J. (2011). Parental Perceptions of Weight Terminology That Providers Use With Youth. Pediatrics, 128(4), e786-e793. doi: $10.1542 /$ peds.2010-3841

Rail, G., Holmes, D., \& Murray, S. J. (2010). The politics of evidence on 'domestic terrorists': Obesity discourses and their effects. Soc Theory Health, 8(3), 259-279.

Rapoport, L., Clark, M., \& Wardle, J. (2000). Evaluation of a modified cognitive-behavioural programme for weight management. International Journal of Obesity, 24, 1726-1737.

Rees, R., Oliver, K., Woodman, J., \& Thomas, J. (2011). The views of young children in the UK about obesity, body size, shape and weight: a systematic review. BMC Public Health, 11(1), 188.

Rich, E. (2010). Obesity assemblages and surveillance in schools. International Journal of Qualitative Studies in Education, 23(7), 803-821. doi: 10.1080/09518398.2010.529474

Rich, E., \& Evans, J. (2005). 'Fat Ethics' - The Obesity Discourse and Body Politics. Social Theory \& Health, 3(4), 341.

Rich, E., Monaghan, L., \& Aphramor, L. (Eds.). (2011). Debating Obesity: Critical Perspectives. Basingstoke, GB: Palgrave MacMillan.

Robison, J. (2003a). The "Obesity Epidemic": An Alternative Perspective. Healthy Weight Journal, 17(1), 1-3.

Robison, J. (2003b). Health At Every Size: Antidote for The "Obesity Epidemic". Healthy Weight Journal, 17(1), 4-7.

Robison, J., \& Carrier, K. (2004). The Spirit and Science of Holistic Health. Bloomington IN: Authorhouse.

Robison, J., Putnam, K., \& McKibbin, L. (2007a). Health at Every Size: A Compassionate, Effective Approach for Helping Individuals With Weight-Related Concerns-Part I. AAOHN Journal, 55(4), 143.

Robison, J., Putnam, K., \& McKibbin, L. (2007b). Health at Every Size: a Compassionate, Effective Approach for Helping Individuals With Weight-Related Concerns-Part II. AAOHN Journal, 55(5), 185.

Ronald, B. (2008). Stigma and the ethics of public health: Not can we but should we. Social Science and Medicine, 67(3), 463-472. doi: 10.1016/j.socscimed.2008.03.017

Saguy, A. C. (2013). What's wrong with fat? New York: Oxford University Press.

Saguy, A. C., \& Gruys, K. (2010). Morality and Health: News Media Constructions of Overweight and Eating Disorders. Social Problems, 57(2), 231.

Saguy, A. C., \& Almeling, R. (2008). Fat in the Fire? Science, the News Media, and the "Obesity Epidemic". Sociological Forum, 23(1), 53-83. doi: 10.1111/j.1600-0838.2004.00399.x-i1

Saguy, A. C., \& Riley, K. W. (2005). Weighing Both Sides: Morality, Mortality, and Framing Contests over Obesity. Journal of Health Politics, Policy \& Law, 30(5), 869-921.

Schafer, M. H., \& Ferraro, K. F. (2011). The Stigma of Obesity. Social Psychology Quarterly, 74(1), 76-97. doi:

\section{$10.1177 / 0190272511398197$}

Schatzki, M. (2011). The Great Fat Fraud. New Jersey, NJ, USA: Lamington Press.

Shelley, K., O'Hara, L., \& Gregg, J. (2010). The impact on teachers of designing and implementing a Health at Every Size curriculum unit. Asia-Pacific Journal of Health, Sport \& Physical Education, 1(3/4), 21-28.

Solovay, S. (2000). Tipping the Scales of Justice: fighting weight-based discrimination. New York: Prometheus Books.

Solovay, S., \& Rothblum, E. (2009). Introduction. In E. Rothblum \& S. Solovay (Eds.), The Fat Studies Reader. New York, NY, USA: New York University Press.

Stearns, P. (2002). Fat History: Bodies and Beauty in the Modern West (2 ed.). New York: New York University Press.

Strategies to Overcome and Prevent (STOP) Obesity Alliance. Retrieved 17 November, 2012, from http://www.stopobesityalliance.org/

Swinburn, B., \& Egger, G. (2004). The runaway weight gain train: too many accelerators, not enough brakes. British Medical Journal, 329, 736-739.

Tanco, S., Linden, W., \& Earle, T. (1998). Well-being and morbid obesity in women: A controlled therapy evaluation. International Journal of Eating Disorders, 23(3), 325-339.

Teixeira, M. E., \& Budd, G. M. (2010). Obesity stigma: A newly recognized barrier to comprehensive and effective type 2 diabetes management. Journal of the American Academy of Nurse Practitioners, 22(10), 527-533. doi:

$10.1111 / \mathrm{j} .1745-7599.2010 .00551 . x$

Thomas, S., Lewis, S., Hyde, J., Castle, D., \& Komesaroff, P. (2010). "The solution needs to be complex." Obese adults' attitudes about the effectiveness of individual and population based interventions for obesity. BMC Public Health, 10(1), 420.

Thomas, S. L., Hyde, J., Karunaratne, A., Herbert, D., \& Komesaroff, P. A. (2008). Being 'fat' in today's world: a qualitative study of the lived experiences of people with obesity in Australia. Health Expectations, 11(4), 321-330. doi: 10.1111/j.1369-7625.2008.00490.x

Thompson, L., \& Kumar, A. (2011). Responses to health promotion campaigns: resistance, denial and othering. Critical Public Health, 21(1), 105-117. doi: 10.1080/09581591003797129

Tylka, T. L., Annunziato, R. A., Burgard, D., Daníelsdóttir, S., Shuman, E., Davis, C., \& Calogero, R. M. (2014). The Weight-Inclusive versus Weight-Normative Approach to Health: Evaluating the Evidence for Prioritizing Well-Being over Weight Loss. Journal of Obesity, 2014(Article ID 983495), 18. doi: $10.1155 / 2014 / 983495$

Vander Schee, C. J., \& Boyles, D. (2010). 'Exergaming,' corporate interests and the crisis discourse of childhood obesity. Sport, Education and Society, 15(2), 169-185. doi: $10.1080 / 13573321003683828$

Wann, M. (1998). Fat!So? Because you don't have to apologise for your size! Berkeley: Ten Speed Press.

Wann, M. (2005). Fat and Choice. Meowpower Feminist Journal Online, 1(3). 
Wann, M. (2009). Fat Studies: An Invitation to Revolution. In E. Rothblum \& S. Solovay (Eds.), The Fat Studies Reader. New York, USA: New York University Press.

Welsh, T. L. (2011). Healthism and the Bodies of Women: Pleasure and Discipline in the War against Obesity. Journal of Feminist Research, 1(Fall), 33-48.

World Health Organization. (2003). Diet, nutrition and the prevention of chronic diseases: report of a joint WHO/FAO expert consultation, Geneva, 28 January -- 1 February 2002 (pp. 1-70). Geneva: World Health Organization and the Food and Agriculture Organization of the United Nations.

World Health Organization. (2006). Controlling the global obesity epidemic Retrieved 28 May, 2006, from

http://www.who.int/nutrition/topics/obesity/en/

Wright, J., \& Harwood, V. (Eds.). (2008). Biopolitics and the 'obesity epidemic': governing bodies. New York, NY, USA: Routledge. 